\title{
Towards Engaged Consumption: New Sources of Inspiration for Eco-feedback Design
}

\author{
Stephen Snow and Margot Brereton \\ Queensland University of Technology, 2 George St, Brisbane, 4001, Australia \\ \{steve.snow, m.brereton\} @qut.edu.au
}

\begin{abstract}
Eco-feedback interventions are capable of producing reductions in household energy consumption. Yet less is known about exactly how this reduction is achieved, how to maximise user engagement, or how to effectively translate engagement into energy saving. This paper discusses design opportunities for eco-feedback systems through observations of domestic energy use in both Western and rural developing world contexts. Drawing on case studies from these two contexts including 21 empirical interviews, we present an alternative framework for human-resource interaction, highlighting design opportunities for a transition towards more engaged and sustainable energy consumption among users.
\end{abstract}

Keywords: Eco-feedback, resource use, electricity, engaged consumption.

\section{Introduction}

Domestic energy consumption continues to grow in saliency in the global consciousness due to its contribution to environmental issues such as climate change and the challenges associated with peak demand [10]. Providing households with improved feedback on their energy use (eco-feedback) has emerged as a fruitful means of addressing these challenges through heightening energy-awareness, better informing consumption decisions and potentially facilitating pro-environmental behaviours $[3,4,5]$. Research suggests that eco-feedback interventions such as energy monitors or interactive in-home displays are capable of producing significant reductions in household consumption, yielding average energy savings of approximately 7 to $14 \%$ for the time they are installed [3]. Less is known however, about the processes through which this conservation effect is achieved or which eco-feedback attributes best facilitate engagement and energy savings [6]. Similarly, while many ecofeedback studies assume a direct link between raised awareness and energy savings [6], social psychology literature suggests heightened awareness is not a reliable predictor of behaviour change [9]. What is clearer is that many Western consumers are substantially disconnected from the energy resources they consume [9] and that ecofeedback has the potential to help bridge this divide [5].

Adopting a broader frame of reference, one could justifiably question the significant amounts of time and effort being invested in this field by HCI researchers, when 
approximately one third of the world's population still rely on burning biomass as their primary source of energy [7]. Despite the peak demand issues being experienced in many parts of the world, $25 \%$ of the world's population still lacks effortless access to electricity [1] and cannot directly benefit from conventional eco-feedback. On the other hand, these populations unwittingly have a far stronger understanding and appreciation of the relationships between their everyday practices and their resource consumption. For instance, they physically gather the energy resources they require in many cases rather than simply flicking a switch or turning a tap.

Considering eco-feedback has the potential to better engage Western consumers with their energy consumption [5], we believe this field of enquiry has much to gain from studying practices of people in less developed countries who are already more engaged in this regard. This can serve to inform the design of eco-feedback technology and in turn, provide inspiration for designs that may benefit these communities as well.

The purpose of this paper is to investigate eco-feedback design through the lens of the human-resource interactions which take place in the home and the underlying infrastructures and mentalities that shape these interactions. Drawing from examples from both Western and rural developing world contexts, including 21 interviews with suburban Australian households, we illustrate the discrepancy in engagement with consumption between the two contexts. We then present a framework for humanresource interaction and highlight some of the many design challenges associated with eco-feedback effectively transitioning users towards more Engaged Consumption.

\section{The Story of Two Worlds of Energy}

\subsection{The Western Context}

The relationship between everyday practices and domestic resource consumption, whilst inextricable, is often poorly understood in Western contexts [10]. The continual disparity between the spheres of production and consumption represents a major obstacle to consumers becoming better engaged with their domestic resource use [9]. Electricity and water consumption for instance result from practices in the household sphere which can be unpredictable, changeable and based on social, cultural or external influences [10]. Yet in Australia, the billing mechanisms for these 'services' still consist of infrequent unitemised invoices which distill the multitude of actions creating the consumption into a single value. This has contributed to a mentality of disinterest among many suburban Australian consumers towards their resource consumption. Sofoulis [9] argues this is at least partly due to the longstanding dominant socio-technical systems for supplying water and electricity. In suburban Australia, large centralised utilities have assumed all responsibility for the supply and (in the case of waste water and sewage) disposal of these resources as a 'service' to their customers [9]. As a result of this centralised municipal system, an illusion is created of 'endless supply' at the other end of a power socket or tap [9]; a misconception that was actively promoted by electricity authorities in previous decades: 
“Now, under the Council's new Tariff of Penny Units... You can use Electricity for every purpose without counting the cost... No need to worry about switching off the lights, but have peace of mind and contentment with a welllighted home. - You can, without being extravagant, use electricity for everything!" (Electricity Topics, Issue 1, pp.8, 1936; reproduced in [8])

The notion of endless supply is further reinforced by the typical home infrastructure related to electricity and water consumption. For instance the positioning of the water and electricity meters external to the dwelling emphasises that responsibility for the management of these resources lies outside of the home [9]. Many years of cheap and stable electricity prices have further reinforced this disengagement among suburban Australians with their energy consumption, thereby limiting motivation to better understand the factors affecting their consumption or adopt conservation practices.

Providing consumers with better feedback on their energy use represents a means of bridging this gap in energy-literacy and facilitating a more Engaged Consumption among consumers. However, considering the weak correlation between awareness and behavior change [9], a key feature of Engaged Consumption and thus a challenge for designers, should be to effectively translate engagement into energy conservation.

\subsection{The Rural Developing World Context}

Despite facing far more significant challenges, disconnection from resource consumption and lack of conservation awareness is not a problem facing many of the hundreds of millions of people living in rural areas in the developing world. For those who remain without effortless access to electricity and water, resource consumption is a far more tangible, visual, physical and social activity [1]. The link between everyday practices and resource consumption is more explicit, for instance, the same user may gather the resources themselves prior to overseeing and regulating their consumption [7]. In this context, feedback on usage is visual and immediate and often requires a prompt response, such as stoking a fire or filling a lamp.

Bidwell et al. [1] report on the design and deployment of solar-powered charging stations for mobile phones in the district of Mankosi on the Eastern Cape of South Africa. For many here, electricity is used for the single purpose of charging phone batteries and the supply source (the sun), the distribution network (wires) and the electricity consumption (phones being charged) can all be visualised within a single line of sight. This visualisation contrasts starkly with the act of plugging a charger into a socket on the wall, which many Western consumers are familiar with. In Mankosi, electricity consumption is often a very explicit social process; locals gathered at the mobile charging stations to chat with the charging facilitator and other locals. Users became aware of the factors affecting consumption such as cloud or rain through such informal conversations [1].

Another disparity between domestic resource consumption in the developing world and the West is the amount paid for electricity; both in terms of financial capital and physical effort. Using the example of Sagar Island in West Bengal, India [2], men and 
boys from villages walk to makeshift battery charging businesses to rent car batteries. These batteries are carried home to provide power for lighting, entertainment and other uses during the evening. For these simple privileges and the social status they afford, villagers exert considerable physical effort and pay the equivalent of 10 times the standard electricity tariff in West Bengal [2]. A similar situation exists in Mankosi [1] where, in the absence of the solar charging stations, villagers walk to establishments with petrol generators and pay around R5.50 ( US\$0.60) to charge their phone when they can afford to. This cost is similarly exorbitant when compared to that incurred by charging a phone battery from a grid-connected dwelling in South Africa $(\sim \mathrm{R} 0.70 \text { or } \sim \mathrm{US} \$ 0.08)^{1}$. In both these examples, users have a high tacit knowledge of the factors affecting battery life and ways to conserve energy $[1,2]$.

\section{Interview Findings - The Australian Context}

In order to explore engagement between Australian consumers and their electricity consumption and to seek design inspiration for eco-feedback systems, we began by interviewing 21 participants living in Brisbane, Australia. While our findings here are limited to suburban Brisbane, over time we aim to balance these with accounts from remote Australian communities including primarily Indigenous communities whose remoteness often dictates they operate more self-sufficiently.

All of our participants lived in dwellings reliant on mains electricity and reticulated water and sewage, with 16 of the 21 having opted to receive a small digital energy monitor as part of a government sustainability initiative. We were not involved in the design or deployment of this monitor and cannot comment on the circumstances in which it was installed in the homes. The monitor displayed aggregate household consumption instantaneously both in kilowatt hours and in dollars. The interview process included a 'tour' of the dwelling and included questions covering the topics of electricity usage behaviour, electricity feedback and the social sharing of information related to electricity.

\section{1 (Dis)engagement with Energy Consumption}

Continuous electricity supply was seen by participants as both a necessity and a right. Despite this, the connection between understandings of the impact of everyday practices upon electricity consumption was found to be somewhat tenuous for many participants. For instance "turning off the lights" was mentioned frequently as a conservation practice, both in relation to the participants themselves and to teaching children. However, considering most participants had replaced their incandescent bulbs with energy saving compact fluorescent varieties, turning off lights often

\footnotetext{
${ }^{1}$ Indicative only; assuming phone charger draws $3.68 \mathrm{~W}$ while charging; phone takes 4 hours to charge; at $\sim$ R47/kWh. Sources: Eksom Schedule of Standard Prices for Local Authority Supplies, South Africa http://www.eskom.co.za/c/article/1090/schedule-ofstandard-prices / and Lawrence Berkley National Laboratory http://standby.1bl.gov/summary-table.html
} 
represented a less effective conservation action than modifications to other comfort, cleanliness or entertainment practices. In eight other instances, while participants were aware of an appliance consuming a lot of power, such as the air conditioning or tumble dryer, its usage was considered non negotiable. Three participants had signed up to a direct debit scheme where an agreed amount was automatically paid to the electricity utility each month, thereby distancing them even further from their bills.

"I don't even get a bill anymore; it's all on line.... I don't even see the little chart with your energy consumption displayed last year versus this year... I used to but not anymore, it just gets automatically paid" (Interview 1)

\subsection{Experiences of Simplistic Eco-feedback}

Despite 16 of the 21 participants having received an energy monitor at some point, only half of these were found to be operable at the time of the interview. While four of these cases can be explained by technical malfunction caused by the install of solar panels, the other cases appeared to be due to neglect or could not be explained. For the remaining eight working monitors, at the time of the interview half were no longer referred to regularly or were found obscured behind other items (Figure 1).
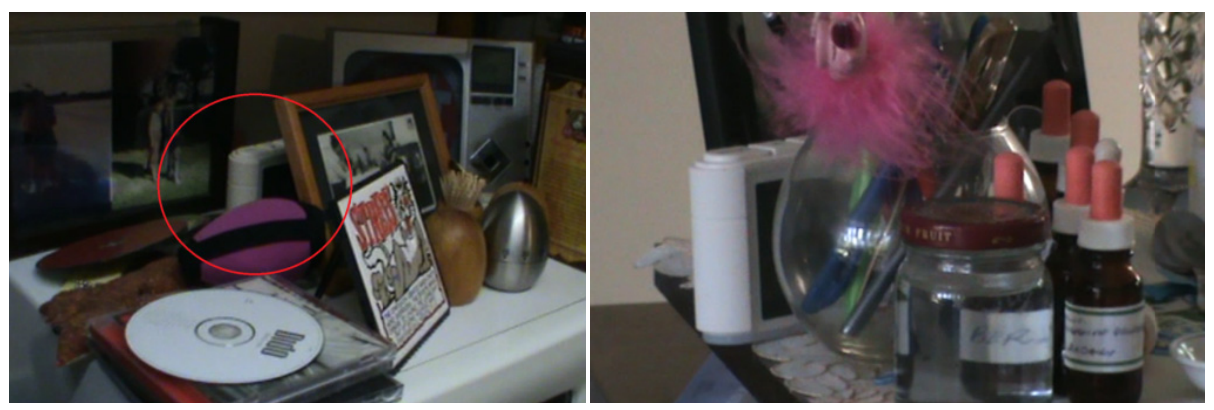

Fig. 1. Two functioning electricity monitors obscured from view

Furthermore, despite the prevalence of the energy monitors among the sample group, all but one participant still relied on the quarterly bill as their main source of feedback on their electricity consumption. Several participants also had trouble reconciling their electricity bills with expectations of what they thought their bills "should" be, resulting in a disbelief or distrust of the utility responsible for generating the bill. These findings correlate closely with Sofoulis's [9] arguments regarding the implicit delegation of responsibility for electricity and water resources to external bodies.

"Sometimes I think the electricity utilities are dudding you all the time... I think they're estimating a lot and I don't trust them.... I have very set pattern of living. And I can't see how my power bill would triple. TRIPLE over a few short years. It doesn't make sense to me" (Interview 10) 
Despite this, all but one of the participants who had received the energy monitor claimed they had drawn some benefit from it at some point. In most cases however, engagement with the device had not been long lasting, or they had experienced difficulty relating the information displayed on it to specific actions or practices.

When we first got it I looked and it and I thought it was fascinating, but I didn't understand it. Like it just says, y'know, 0.68 or something and I went "that's interesting", but I couldn't relate it to (anything)... I know obviously the lesser the figure the better it is, but that's all. (Interview 20)

Nearly all of the participants stated they would like additional feedback. In relation to their "ideal" electricity feedback system, the only attribute that was consistently mentioned as being desirable across the whole sample group was the provision of appliance specific feedback. This finding correlates with those of other HCI researchers in the field [5]. The desirability of many other attributes, for instance spatial comparison, social comparison, positioning and means of accessing feedback varied, with these attributes being desirable to some participants and undesirable to others.

\subsection{Conversations Related to Energy Consumption}

Finally, we found an interesting disparity between participants' accounts of their conversations regarding (1) electrical appliances that contribute towards energy consumption and (2) absolute measures of consumption such as electricity bills. While appliances were discussed by most participants in social circles and between friends, especially prior to making a purchase; only six of the 21 interviewees mentioned they shared their bill amount with anyone outside of their immediate family. This does not mean that the bill was considered a secret or private thing, as only three participants described it as such, but simply that conversations regarding measurements of electricity consumption were generally contained within the family home, whereas conversations about appliances and their use were shared.

\section{Towards Engaged Consumption - Design Opportunities}

Through our case studies and interview findings, this paper illustrates a considerable disparity in engagement with domestic resource use between suburban Australian and rural developing world contexts. Therefore we raise the question of: what lessons can be learnt from resource use in the developing world toward better engaging Australian consumers with their consumption?

To address this, we highlight design opportunities for a transition towards a new framework for human-resource interaction involving more Engaged Consumption among consumers. Here we draw inspiration from our case studies, interview findings and findings made by other researchers. Table 1 presents an overview of our framework and we explain some important characteristics in better detail below. 
Table 1. A framework for Human-Resource Interaction comparing current experience in Mankosi, West Bengal and Suburban Australia with the vision of a more informed and environmentally aware Engaged Consumption

\begin{tabular}{|l|l|l|l|}
\hline $\begin{array}{l}\text { Human/Resource } \\
\text { Interaction }\end{array}$ & $\begin{array}{l}\text { Mankosi / Sagar } \\
\text { Island }\end{array}$ & $\begin{array}{l}\text { Suburban } \\
\text { Brisbane }\end{array}$ & $\begin{array}{l}\text { Engaged } \\
\text { Consumption }\end{array}$ \\
\hline $\begin{array}{l}\text { Effort expended to } \\
\text { access energy re- } \\
\text { source }\end{array}$ & $\begin{array}{l}\text { High: Walking; gather- } \\
\text { ing; carrying }\end{array}$ & $\begin{array}{l}\text { Low: Flicking a } \\
\text { switch, turning a tap } \\
\text { etc. }\end{array}$ & $\begin{array}{l}\text { Low/Medium: Effort } \\
\text { required to purchase } \\
\text { electricity credit and } \\
\text { to monitor energy use } \\
\text { through feedback }\end{array}$ \\
\hline $\begin{array}{l}\text { Perceived Benefit/ } \\
\text { value }\end{array}$ & $\begin{array}{l}\text { Luxury item; } \\
\text { social status and con- } \\
\text { nection; more usable } \\
\text { hours in the day }\end{array}$ & $\begin{array}{l}\text { Assumed necessity; } \\
\text { lifestyle }\end{array}$ & $\begin{array}{l}\text { Informed and reduced } \\
\text { usage, cost; better } \\
\text { control over consump- } \\
\text { tion }\end{array}$ \\
\hline $\begin{array}{l}\text { Awareness of } \\
\text { resource consump- } \\
\text { tion, cost }\end{array}$ & $\begin{array}{l}\text { High: Resource con- } \\
\text { sumption is tangible; } \\
\text { cash paid for given } \\
\text { quantity of electricity } \\
\text { prior to usage }\end{array}$ & $\begin{array}{l}\text { Low: Little apprecia- } \\
\text { tion of resource use; } \\
\text { infrequent bill; } \\
\text { no point of sale } \\
\text { information }\end{array}$ & $\begin{array}{l}\text { Higher: Appliance } \\
\text { and practice-specific } \\
\text { feedback on usage; } \\
\text { cumulative bill }\end{array}$ \\
\hline $\begin{array}{l}\text { Sociability of re- } \\
\text { source consumption }\end{array}$ & $\begin{array}{l}\text { High; talking while } \\
\text { charging, walking; } \\
\text { sharing information }\end{array}$ & $\begin{array}{l}\text { Low; bills discussed } \\
\text { mainly within the } \\
\text { home }\end{array}$ & $\begin{array}{l}\text { Higher: more social } \\
\text { learning about } \\
\text { electricity }\end{array}$ \\
\hline
\end{tabular}

Based on Strengers [10], we consider a key attribute of Engaged Consumption is eco-feedback that enables users to relate their resource consumption to everyday practice. This is something that is more easily done at present in Mankosi or Sagar Island than in suburban Australia. For instance, in developing world contexts, paraffin may be used for lighting; wood or coal used for heating and cooking; and electricity for entertainment and communication [7]. In many of our participants' dwellings however, electricity was used for all of these purposes. As such, one possible design strategy for eco-feedback systems could be to provide people with both appliance-specific (e.g. microwave, cooktop) and practice-specific (e.g. cooking) feedback on usage.

In relation to Engaged Consumption effectively facilitating energy conservation, we highlight three aspects of resource use in the developing world which serve to shape conservation. These include the physical effort required to obtain resources, the timing of payment for them and the consequences of wastage. On Sagar Island for example, electricity use is defined by the physical effort and high cost involved with the battery rental process [2]. Money is paid for a given quantity of electricity prior to its use and a direct consequence of injudicious usage is no electricity for the remainder of the evening or further physical effort and money spent renting a new battery. For many of our participants however, there were no clear indicators of electricity wastage, no physical consequences of wastage and the economic consequences would not become apparent to them until the next quarterly bill.

Considering it may be unrealistic to introduce physical activity as a pre-requisite for access to electricity in Western contexts, we focus on two more achievable reforms to human-resource interaction aimed at translating engagement into energy 
conservation. These are: (1) better feedback on inefficient use and; (2) bringing the physical payment for the energy closer to the point of consumption. We consider introducing or at least simulating (through eco-feedback) a system of pre-payment for energy resources to be a key component of Engaged Consumption. In a pre-payment scenario, the user 'gathers' credit and has an obligation to monitor and control usage such that their credit, along with their power or water supply, does not run out before the credit is recharged. Eco-feedback is fundamental in any pre-payment scenario by providing users with information on their consumption and their remaining credit, thereby positioning price at the forefront of consciousness and counteracting the notion of 'endless supply'. Opportunities exist here for eco-feedback that delivers powerful visual representations of money dripping away or energy credits disappearing. Furthermore, utility-led systems for energy pre-payment are already available in areas of both the Western and developing world and when combined with eco-feedback have produced impressive energy saving results [3].

A final design opportunity that we highlight as a potential means of achieving Engaged Consumption is that of sharing information related to electricity. While electricity use was found to be a highly social process in Mankosi [1], we found that less than one third of our interviewee respondents shared any billing or usage information with those outside of their immediate family. We conclude by encouraging HCI designers to look for opportunities for how eco-feedback can better facilitate information sharing and social learning about energy use between friends and family.

\section{References}

1. Bidwell, N.J., Siya, M., Marsden, G., Tucker, W.D., Tshemese, N., Gavin, S., et al.: Walking and the social life of solar charging in rural Africa. In: Proc: TOCHI (2013)

2. Dadiomov, D.: Power trips. Stanford Magazine (May/June 2012), http://alumni.stanford.edu/get/page/magazine/article/ ?article_id=53335 (accessed March 20, 2013)

3. Faruqui, A., Sergici, S., Sharif, A.: The impact of informational feedback on energy consumption-A survey of the experimental evidence. Energy 35(4), 1598-1608 (2013)

4. Froehlich, J., Findlater, L., Landay, J.: The design of eco-feedback technology. In: Proc: CHI 2010, Atlanta, Georgia (2010)

5. Froehlich, J., Findlater, L., Ostergren, M., Ramanathan, S., Peterson, J., Wragg, I., Larson, Fu, F., Bai, M., Patel, S.H., Landay J.: The design and evaluation of prototype eco-feedback displays for fixture-level water use data. In: Proc: CHI 2012, Austin, Texas (2012)

6. Hargreaves, T., Nye, M., Burgess, J.: Making energy visible: A qualitative field study of how householders interact with feedback from smart energy monitors. Energy Policy 38(10), 6111-6119 (2010)

7. Howels, M.I., Alfstad, T., Victor, D.G., Goldstein, G.: A model of household energy services in a low-income rural African village. Energy Policy 33, 1833-1851 (2005)

8. King, J.: Power for the people: Brisbane electrical heritage 1880s-1950s. Published by Queensland Energy Museum, Brisbane (2003)

9. Sofoulis, Z.: Big water, everday water: A sociotechnical perspectice. Journal of Media and Cultural Studies 19(4), 445-463 (2005)

10. Strengers, Y.: Bridging the divide between resource management and everyday life: Smart metering, comfort and cleanliness. RMIT University (2009),

http: //researchbank.rmit. edu.au/eserv/rmit:6820/Strengers.pdf (accessed March 19, 2013) 